\title{
Transformative Choices and the Specter of Regret
}

\author{
By Dana Howard \\ Ohio State University \\ howard.1146@,osu.edu
}

\begin{abstract}
When people are making certain medical decisions - especially potentially transformative ones - the specter of regret may color their choices. In this paper, I ask: can predicting that we will regret a decision in the future serve any justificatory role in our present decision-making? And if so, what role? While there are many pitfalls to such reasoning, I ultimately conclude that considering future retrospective emotions like regret in our decisionmaking can be both rational and authentic. Rather than indicating that one is about to make a mistake or that there is some underlying value that one already cares about but is overlooking, the prediction that one will regret a decision in the future makes one confront how her present values and priorities may change as a result of her choice in ways she cannot presently anticipate.
\end{abstract}

Keywords: Moral Psychology, Practical Reason, Transformative Experiences, Medical Ethics, Regret

Acknowledgments: Thanks to Elizabeth Barnes, R. Lanier Anderson, Justin D'Arms, L.A. Paul, David Plunkett, Benjamin McKean, Emma Saunders-Hastings, Larisa Svirsky, Rebecca Stangl, Rosa Terlazzo, and Alex Voorhoeve for guiding comments and discussion on this paper. Thank you also to the participants at Stanford University Center for Ethics in Society Junior Scholars Workshop, University of North Carolina Chapel Hill Working Group, Dartmouth College Workshop, and members of the University of Virginia Philosophy Department and Bioethics Program.

When people are making certain medical decisions, the specter of regret may color their choices. This paper asks: Can predicting that we'll regret a decision in the future serve 
any justificatory role in our present decision-making? And if so, what role? I am particularly interested in how predicting regret can play a role in decisions concerning transformative experiences, i.e., having a child, undergoing major surgery, losing a loved one. When we make such decisions, we are in part choosing whether to undergo certain experiences that shape us as people and may profoundly affect our values but for which we cannot know in advance what it will be like to undergo. As we confront these transformative choices, we are in a position of what L.A. Paul calls 'epistemic poverty'; prior to the decision we lack "crucial information about the preferences and perspectives of [our] possible later selves" (Paul 2015b, 765). We cannot grasp the phenomenal character of these potential outcomes and so we have difficulty determining their subjective value. It is thus no longer business as usual when it comes to our practical decision-making; since we cannot assign subjective values to all possible outcomes of our decision (along with their correlative probabilities), we cannot weigh all these relevant considerations against each other.

Given this predicament, we have to go back to our deliberative toolbox to consider what strategies are available to us in order to make these important life-changing choices in a manner that is both rational and authentic. One tool that may be of use is the capacity to anticipate certain future emotional responses such as future regret (as well as future guilt, future pride, etc.) and incorporate those predicted responses into our decision-making. I will be focusing on anticipating future regret and will examine whether employing this sort of deliberative strategy is rational - that is, whether it is guided by our reason and counteracts our biases. In the final section, I will consider whether such a strategy is authentic - that is, whether it enables us to shape our lives from our distinctive first-personal perspective. Ultimately, I argue that such a strategy can be both rationally and authentically employed, but it's also a strategy that can easily be distorted and abused.

I will focus specifically on decisions made in medical settings, though the lessons drawn from the discussion are generalizable. There are a number of reasons to turn our attention to the medical setting. First, the medical setting presents us with real cases of people deliberately making transformative choices. Whereas some transformative experiences happen to us without our anticipation or against our will - losing one's religious faith, surviving warthe medical setting is one place where we recognize that the choices we make can change both our epistemic position and our character in ways that are subjectively inaccessible to us as we make them. Second, medical decisions concern changes in one's body, one's cognitive capacities, one's perception, and one's physical functioning. The phenomenal character of these sorts of changes is not the sort of thing we can easily assess. The limitations of our capacity to imaginatively project ourselves into such future scenarios are palpable and are pervasive features of such decisions. Third, these medical decisions are often irreversible once we come to know the subjective value of the outcomes of our choice, we cannot go back and alter our course of treatment accordingly. Fourth, medical decisions are often time sensitive and cannot be deferred. The medical setting is thus one in which transformative choices must be made even in the face of great uncertainty and with the likely prospect of shifting values (Walsh 2020, Boerslter 2017, Chung 2017).

In spite of all these epistemic limitations and difficulties, people agree that it's fundamentally important that these decisions are ones that patients make for themselves (insofar as they have the capacity to do so). Rather than solely focusing on the objectively best decision for a person, medical decisions are often understood as deeply personal. In evaluating 
such decisions, we focus on whether a choice is authentic to our life and character (ie. that it enables us to continue to shape our lives as we see fit) as much as we focus on whether the outcome of the decision maximizes our interests. Giving up our autonomy by outsourcing these very personal decisions to medical professionals or public health experts or some other third party is an untenable option for us (Paul 2014, 139). All of these features conspire to make our medical choices paradigmatically transformative and incredibly challenging.

Consider the following cases:

\section{THREE CASES}

Vaccination Regret: It has long been assumed that parental reluctance to vaccinate one's children may be the result of an "omission bias" - a general tendency to prefer inactive to active options even when inaction leads to worse outcomes or to greater risks. But some studies have suggested that parents reluctant to vaccinate their children may be motivated less by their preference for inaction and more by regret avoidance. Those reluctant to vaccinate more often predict that they would feel a higher level of regret if vaccination led to some negative side effects compared to the level of regret they would feel in response to similarly serious negative outcomes of non-vaccination. Their choice may thus reflect an inclination to minimize the regret they predict they would feel in the face of bad outcomes (Connolly and Reb, 2003; Ziarnowski, et al. 2009).

Abortion Regret: The ProLife Alliance, an anti-abortion advocacy group, describes abortion as a procedure that many women come to 'bitterly regret' and notes that 'while many women regret having their abortions, few regret having their babies' (Greasely 2012, 705). This argument has gotten purchase in the United States Supreme Court, where the possibility of regretting abortions has led Justice Anthony Kennedy to worry about the possibility of informed consent to certain abortion procedures: "While we find no reliable data to measure the phenomenon, it seems unexceptionable to conclude some women come to regret their choice to abort the infant life they once created and sustained... The State has an interest in ensuring so grave a choice is well informed" (Gonzales v. Carhart, 2007).

Chemo Regret: Patients undergoing bone marrow transplantation for recurrent lymphoma often say that they have no choice but to opt for difficult medical procedures such as high dose chemotherapy and autologous stem cell transplantation (ASCT). These are patients who have likely already undergone chemotherapy, though probably not as intense as ASCT. The chemotherapy associated with ASCT is so strong and the transplant compromises one's immune system to such an extent that patients may remain in isolation in the hospital for the first month of recovery. When thinking about their medical options, these patients often view death to be the only alternative to ASCT, which amounts to no choice at all. After experiencing the painful ordeal of 
ACST, however, a significant number of patients say that they would not consent to it again, expressing regret for having chosen the suffering caused by the treatment. The implicit preference to accept palliative care is recognized only in retrospect (Little 2008, 2009).

These three cases depict the specter of regret entering the medical decision process in a variety of ways. Notably, what is up for debate is whether predicting regret can play a justificatory role in each of these cases and not merely a motivating role. In the case of Vaccination Regret, the prediction that one course of action would be more regrettable than another course action seems to influence (perhaps only implicitly) parental decision-making. The question I want to consider here is whether it can play any role in justifying these parents' decisions.

In the case of Abortion Regret, the specter of regret is something that anti-abortion advocates appeal to in order to discourage women from choosing the procedure. This discouragement may or may not be a form of rational persuasion: are abortion opponents offering a reason to forgo the procedure by bringing up future regret or are they merely using the negative valence of regret to undermine women's confidence in their reproductive decisions? The question of whether expressing such arguments constitutes rational persuasion does not settle its moral permissibility; rational persuasion could be unwelcome, insulting, and paternalistic (Tsai 2014). But it does bear on how such arguments should feature in one's own practical deliberation. If it turned out that having an abortion puts one at a greater risk of future regret, would this fact in itself constitute a reason to forgo the procedure?

In the case of Chemo Regret, there is no anticipated regret affecting the decisionmaking; such emotions only come in after the treatment ordeal. This leads the researcher in the study, Miles Little, to wonder if these patients are making sufficiently informed medical decisions when it comes to these grueling procedures. He subsequently suggests that along with presenting to patients the available treatment options and their associated risks, clinicians should also - as part of their advisory role - broach the subject of what patients may end up coming to regret (Little 2009). It isn't clear, however, precisely what information is missing in the patients' decision-making process prior to undergoing the chemotherapy that reflections on future regret are supposed to supplement. After all, the prospect of pain surely is being considered by these patients and does not presently count as a decisive consideration against the procedure. These are patients who are somewhat familiar with the risks associated with chemotherapy. Should the prediction that the procedure will be so overwhelmingly taxing as to warrant post-treatment regret make any normative difference to the patients now?

Each of these three cases also involves a transformative choice - that is, in each case someone is deciding whether or not to undergo a transformative experience. There are two different ways in which an experience can be transformative: it is epistemically transformative if you can only gain access to information about what that experience is like by undergoing it (Paul 2015a, 155). Accordingly, prior to an epistemically transformative experience, you cannot project what it will be like to have had that experience. An experience is personally transformative if it "radically changes what it is like to be you" (Paul 2015a, 156). Once you undergo a personally transformative experience your priorities, values and self-conception are significantly altered. When an experience is both epistemically and personally transformative, 
not only can you not know what it will be like to undergo the experience, you also cannot know what it will like to be you as a result of that experience.

These three cases involve choices about experiences that have the potential to be transformative in these two interrelated ways. For instance, undergoing brutal chemotherapy can involve a transformative experience. The sheer subjective inaccessibility of such an experience causes Little to worry that his patients may lack the ability to give informed consent: "We conclude that, at least in this small cohort of patients, ASCT is not something that could be adequately communicated. It is not, indeed, possible to convey the experience of any extreme treatment, however conscientiously the clinical staff may try. No amount of telling can create the experience in the listener. Only the experience itself can take the patient through its threats, its pain, loneliness, despair and degradation (Little, et. al. 2008)." The experience seems to significantly alter the priorities and values of some patients - whereas prior to ASCT, a chance of survival swamped out all other alternatives, after undergoing the procedure other interests creep back into their evaluative horizon. Palliative care emerges as a distinctive alternative whereas before the patients saw themselves as facing a choice solely between death and ASCT.

In the case of Abortion Regret, at least as the opponents articulate it, having an abortion itself can be a transformative experience. Consider, for instance, how Allan E. Parker, Jr. a prominent opponent of abortion describes the procedure: "The abortion industry is trying to make it sound like abortion is a joyful experience. But even women who say it was necessary say it was not joyful. It is a grief and a blackness, and it changes you." (Liptak 2016) Regardless of whether one agrees with this description, it's difficult to dismiss the view that the alternative to having an abortion - namely, carrying the pregnancy to term - is a paradigmatically transformative experience in both the personal and epistemic senses. So the decision to have an abortion involves whether or not to undergo at least one sort of transformative experience. Similarly, in the case of Vaccination Regret, the choice to vaccinate or to refuse vaccination involves the possible transformative experience of having a very ill child and potentially losing that child to a preventable disease.

These three cases allude to situations where one's predicted regrets are based either on the tendency for other people in one's position to experience regret (Abortion Regret, Chemo Regret) or on one's own assumptions that certain outcomes are going to elicit a certain level of regret (Vaccination Regret). There are grounds to be skeptical of both of these avenues as ways to come up with reasonable predictions that one will come to regret one's choice. For predictions that are based on statistical information or the testimony of others, it's difficult to evaluate how such information is applicable to one's own case (Paul 2014, 45-47). On the other hand predictions about future attitudes based on one's own present assumptions may not be very reliable (Gilbert et. al., 2004; Loewenstein and Shkade, 1999). For much of the paper, I am going to presume that there are at least certain situations in which we can reasonably predict our regrets and investigate how such predictions play a role in our decisionmaking. In $\ 5$, I will return to the question of whether it's reasonable in these particular cases to predict that one will regret one's choice.

\section{THE DISTINCTIVE FEELING OF REGRET}


To start, let us look at Daniel Jacobson's account of regret, which contains three separate and important features: (1) Regret is Evaluative: Regret involves an evaluative presentation of oneself as having made some bad choice (Jacobson 2013; D'arms and Jacobson 2000, 66-67). (2) Regret is Affective: Regret is itself a painful emotion; it's not merely a dispassionate assessment that some outcome is regrettable. (3) Regret is Motivational: Regret involves the motivation to undo the damage that one's choice has caused and to change one's policy about how to act in similar situations in the future. This motivation to change one's policies may be idle since one may very recognize that there will be no next time. On this definition, regret is warranted only when its evaluative presentation is verdictive - when one really did make a bad choice. Here is a tentative definition drawn from Jacobson's account of regret with one minor - but I think significant - alteration:

Regret: The syndrome of painful feelings of self-reproach focused on one's bad choice and its consequences, accompanied by a wish to undo the choice and an intention to act differently next time.

This definition is taken from Jacobson's description of Chamberlain's regret over his appeasement strategy with Hitler (Jacobson 2013, 105). My one alteration: whereas I define regret as self-reproach focused on one's "bad choices," Jacobson describes Chamberlain's regret as focused more specifically on "his blunder and its disastrous consequences." As I will argue, Jacobson unduly limits his account when he claims that regret ought to be focused on mistakes or blunders and their consequences rather than simply on bad choices. How we want to interpret the idea of making a regrettable 'bad choice' is of great significance. Jacobson argues that regret involves the evaluative presentation of oneself as having made a mistake. For him, the criterion for the rationality of regret is whether or not one has actually erred, not merely whether one has decided in a way that has brought about significant loss (Jacobson 2013, 106). So having made a mistake is a constitutive feature of regret because otherwise regret would not be able to serve its motivational role of triggering a policy change.

I think that this criterion of judging one's past choice as mistaken is too restrictive, especially when we consider transformative choices, and I will return to why in $\$ 4$. But for now, I want to allow for the following sorts of evaluative judgments to be aligned with the feeling of warranted regret: "I made a decision under uncertain circumstances; I took a reasonable risk. It didn't pay off." Sometimes the choices we make are bad because of a mistake in our judgment and we are warranted to regret those mistakes. Other times, our choices are bad just because we passed up on options open to us that could have turned out to be so much better. Regret is fitting in regards to those choices as well. Were I to sell my $\$ 5$ lottery ticket that has a .001\% chance at winning a million dollars to my butcher for $\$ 20$ and then it wins, it would be no consolation to me that I made the right decision given my odds. I am warranted to regret what I don't see as a mistake. It was a bad choice because of how it ended up panning out as compared to how things could have turned out had I decided otherwise. At its heart, regret tracks the bare fact that we had a real choice to make and the choice we made constituted a significant loss.

Regret is the paradigmatic counterfactual emotion. In regret, we are comparing the outcomes of our choice with how things could have turned out had we chosen differently (Loomes and Sudgen, 1982, Zeelenberg 1999). This is different from disappointment where one is comparing the outcomes of a particular choice against what one had expected (or 
hoped) the outcomes of that choice would be. We feel disappointment when our lottery ticket turns out to be a loser; we regret buying the ticket in first place.

Another important feature of the emotion is that regret needn't be experienced as a morally valenced emotion. For clarification, juxtapose regret with a structurally similar account of remorse.

Remorse: The syndrome of painful feelings of self-reproach focused on one's past moral transgression, accompanied by a wish to make amends for the transgression and an intention to act differently next time.

Remorse and regret often come together. Both are painful retrospective emotions that involve self-reproach along with the motivation to change one's ways. However, each emotion fixes on slightly different features of one's actions. Remorse is distinctively responding to not living up to one's moral obligations. Thus remorse could be fitting in response to one's decisions that wrong others - by putting them at risk, or by disregarding their interests - but that ultimately brings about excellent consequences for all parties. Imagine a parent betting his child's modest college fund at the casino. The bet pays off, the college fund quadrupled. The parent's remorse is still fitting in such a case, while regret seems misplaced. The parent may still be motivated to change his ways (he should not expect to be so lucky next time), but it would be unfitting for him to wish to undo his choice. Such a wish would amount to fastidiously caring about getting each decision right regardless of how undoing such a decision (ie. giving the money back to the casino) would end up affecting others. On the other hand, we could feel regret for decisions that lead to bad consequences even when we don't think we did anything morally wrong. We can regret an innocent mistake since they often lead to disastrous consequences.

One may want to argue that if we were truly to understand the past choice as the product of an innocent mistake, then regret would be unwarranted. Regret, at its heart, is a painful feeling of self-reproach and if there was no mistake in judgment, then there is no cause for self-reproach of any kind. This response reasonably understands self-reproach specifically as inward-looking blame. However self-reproach can be understood more broadly in terms of self-punishment, involving attitudes of blame, shame, dismay, complicity, and other general painful and obsessive dwellings on the past choice that one has made.

Where we often take our feelings of remorse to be constrained by what is actually in our control, the self-reproach of regret is more expansive in what it attaches to. Our feelings of regret are reflective of both the power and the limits of our agency as it relates to the world that contains it (Wallace 2013). Through our decisions, we have the power to make an impact on the course of the world, but these decisions also set in motion a sequence of events that we cannot fully anticipate or control (Williams 1981). This is just what it means to be an agent and what it means to be prone to regret. The experience of regret is one in which we recognize that an exercise of our agency has in some sense made things not as good as they could have been either for ourselves or for others.

Along with a fuller picture of what is distinctive about the experience of regret, we want a better sense of what counts as predicting future regret. It is useful then to distinguish anticipating retrospective emotions in the future like future regret or future remorse from feeling 
anticipatory emotional responses toward the future such as dread or despair. The feeling of dread can be characterized as a painful anticipation of a guaranteed bad outcome. We feel dread only when we have at present a negative evaluation of this future outcome. Similarly, despair can be characterized as a painful yearning for a specific positive outcome that one anticipates will not transpire. Again, we feel despair only when we have a present negative evaluation of the future outcome. In contrast, when we anticipate future retrospective emotions such as regret, there need not be any affective component at present. All we are doing is determining the high likelihood of the negative retrospective sentiment in the future. Such a determination does not even require that we presently hold the same negative evaluation of the future outcome.

This is an important feature of how our anticipated future attitudes can play a distinctive role in our decision-making. It is sometimes hard to keep in full view all the relevant considerations for our decision, especially given certain biases we have toward the present. Incorporating our predicted attitudes into our deliberation may allow us to access distal goods and distal losses and measure them up to our present concerns (Moller 2011, 11). Moreover, we tend to undervalue the goods we already have and overvalue goods we lack (D'arms and Jacobson 2009, 194). Anticipated retrospective attitudes such as regret may focus our attention on certain losses we may not be (perhaps reasonably) valuing at present.

Now one may worry that such subtle differences between regret and remorse, between anticipatory emotions and anticipating retrospective emotions, are taxonomical distinctions that are philosophically interesting but have little purchase in our daily lives or in normal decision-making. I don't presume that these distinctions are present in the minds of, say, those parents who are thinking about vaccinating their children. However, these distinctions are tracking real differences in our emotional repertoire. We can pick out phenomenological differences between these emotions even if we cannot articulate precisely what these differences entail.

Moreover, these distinctions are salient in the three cases presented at the outset. In the case of Chemo Regret, although patients most certainly feel disappointment when the results of ASCT don't lead to the eradication of their cancer, it is their expression of regret for choosing the treatment in the first place that makes Little question whether they were making adequately informed decisions prior to the experience of ASCT. And it isn't accidental that abortion opponents are using the language of regret rather than remorse. A different sort of argument is made by opponents of abortion with the claim that many women feel remorse after having abortions. The specter of regret approach is at least prima facie morally neutral; it is purportedly about the women's prudential interests rather than about a moral obligation that they may have toward the unborn fetus.

This is a key strategic feature of the argument for a number of reasons. First, since we can regret even innocent mistakes, bringing up the likelihood of regret does not accuse women outright of being culpable for their inclination to have abortions. It does, however, intimate that a choice resulting from this inclination is a bad one for women to make - perhaps bad in ways they're unable to discern presently. Second, regret concerns whether one has chosen the best of her options rather than whether one has chosen a morally permissible option. The specter of regret is thus not as easily dismissed by women who don't take themselves to have any moral obligation to continue the pregnancy. Were I to be told that more women come to feel remorse over their abortions than come to feel remorse over giving birth, this would likely 
have little relevance to my decision-making. I have a pretty settled view on the moral permissibility of abortions, so I have little reason to think that I will be remorseful after the fact. And if remorse would take hold of me, I presently don't take myself to have any reason to think that this future remorse would be warranted. The prediction of regret works on a different register. If it is truly the case that we can be warranted in regretting a sequence of events that was set in motion by our choices but that we cannot fully anticipate or control, then perhaps there is something about the choice that I am not fully anticipating at present. This possibility, I take it, is what abortion opponents are banking on.

\section{IS IT THE PAIN OF REGRET THAT MATTERS?}

It is unsurprising that the specter of regret can play some affective role in pushing people to make certain decisions. Regret can be painful and unrelenting after all. It is an emotion we are happy to avoid when possible. In this sense, there is a very straightforward way in which the prediction that we'll regret a decision in the future may serve a justificatory role in our present decision-making - we are justified in doing what we can to avoid painful feelings down the line. So whenever regret is a predictable outcome of a particular choice, it counts against that choice and must itself be taken into consideration into our decisionmaking. In this way, the prospect that we'll regret some action in the future provides us with a 'hedonic justification' for not doing it (D'arms and Jacobson 2009, 180).

We should note two things about this sort of justification: First, considered hedonically, our predicted regret constitutes a reason to avoid certain actions regardless of whether or not we deem the regret to be warranted. It is the pain of the regret that we have a reason to avoid and we can be in the grip of this painful sentiment against our better judgment (Jacobson 2013, 103). Second, the pain associated with the predicted regret is only one (perhaps minor) consideration among many that is to be taken into account. In principle, it can serve as a tie-breaker and swing the balance of considerations against the predictably regretted action (D'arms and Jacobson 2009, 181). This happens in situations where one is deciding whether to take advantage of once-in-a-lifetime opportunities: should you continue at your secure job or drop everything to become a reality show contestant? The nagging lifelong regret you anticipate were you to pass up the singular experience might suffice to shift the balance of reasons; and it might suffice even if you currently think that the nagging regret would be silly and unwarranted.

Does the hedonic justification apply in the above three cases? It would be strange indeed if the anti-abortion advocates brought up the specter of regret just to warn women about a painful emotion that may result from having an abortion. They don't seem to be saying, "Why yes, there are considerations on both sides as to whether to have an abortion. Given your interests and values it really is a close call. But have you thought about this painful regret that you might feel as a result of the procedure? Forget about whether it's warranted or not, what really matters is that it sure is a nasty emotion. Best avoid it and keep the kid." Rather anti-abortion advocates seem to bring up regret with the aim of persuading women to believe that insofar as they're indifferent between their two options, they're making a grave mistake. The future regret is thus not proposed as a tie-breaker but rather as an indication that 
something has gone awry in the decision-making process of a woman who is inclined to have an abortion.

Related points could be made in regards to Vaccination Regret and Chemo Regret. These cases allude to a potentially deeper way in which anticipating regret can play a role in our decision-making. There is a difference between preferring to not regret what one does and preferring to not do what one will regret. It is this second sort of preference that seems to be at play in these cases. If the specter of regret only counts against a choice because of its consequent painful valence, then decision-makers would have as much reason to find ways to extinguish the painful feelings of regret (i.e. taking some antidepressants, undergoing psychotherapy) as they would to change the behavior that elicits the regret in the first place (Moller, 2011). In many cases, however, when we predict we'll come to regret some decision, this tracks something about the badness of the decision itself and not just the badness of the feelings that result from the decision. In the next two sections, I will examine whether and how anticipating regret in the future can give us a reason at present to think that we should alter our potentially regrettable behavior.

\section{FUTURE REGRET AS A HEURISTIC FOR A MISTAKEN DECISION}

So the pain of regret is of limited use in our deliberation - at least in the three cases under consideration. However, another possible way in which our anticipated regrets can be put to use is as a heuristic device (Moller 2011, 8). Rather than having any independent reasongiving force, the prospect of future regret can make us aware of a consideration that presently counts against a decision. Call this, the 'Heuristic Model' for the justificatory role that predicting regret can play in our present decision-making.

I will defend a version of the Heuristic Model, but the model can be construed in a number of different ways. It is important to be clear on precisely what anticipating regrets is a heuristic for. On one construal, when we predict that in the future we'll regret a decision that we are about to make and we consider such future regret to be warranted, this is indicative that the decision we are about to make is a mistake. Call this the "Heuristic for Mistaken Judgment Approach”.

On this approach, our predictions of regret only serve a justificatory role when we can be plausibly believe that the future regret would be warranted. Consider the following case:

Buying a Car: You are thinking about buying a certain car and it happens to be the case that $80 \%$ of the people who buy that car end up regretting their decision to do so. If you don't have any reason to believe that your car preferences are any different from the preferences of other buyers, you may reasonably predict that you too will come to regret the decision. This seems like critical information to consider in your decision whether to buy the car. (Greasely, 2012)

The critical information in this case isn't the likelihood of regret per se but rather what the regret indicates. Plausibly, the fact that people regret their decision to buy the car is grounded in some bad feature of that model of car - some feature which you already take as relevant to your present decision-making and accordingly shouldn't overlook. The bad feature 
could be related to the car's durability, or its safety, or depreciation rate, etc. These are considerations that you currently care about and if you are not giving them due weight in your deliberations, you are making a mistake. If you knew, for example, that people regret the car because it quickly depreciates in price, then it's the depreciation that would count against buying the car not the regret in and of itself. If, on the other hand, the depreciation in price isn't something that you presently care about or is something that you have already taken into consideration in your deliberations, then learning that other people regret their purchase because of this feature should not make a normative difference in your decision-making. The regret serves no independent reason-giving role. Call this phenomenon, 'the normative transparency of regret'.

On the Heuristic for Mistaken Judgment Approach, a general principle emerges about how our predicted regrets can guide our present decision-making:

Transparency of Regret Principle [TRP]: The prediction that you will come to regret a decision should count against making that decision only insofar as the anticipated regret points to some underlying consideration which you already take to count against that decision.

TRP is plausible. It can explain why the pain of anticipated regret can at times justify one's decisions and at other times fail to justify them. When I am truly indifferent between two alternatives (e.g. stay at my job or compete in a reality show), the pain of future regret is something that I care to avoid right now and this can appropriately make a significant difference in my decision-making. If I ignore the pain of the future regret, I am making a mistake. On the other hand, in the case of Vaccination Regret, the parent may care at present about avoiding future painful feelings, but such a care doesn't seem to appropriately count as a consideration in her present decision about whether to vaccinate their child - even as a tiebreaker. If the parent ignores the pain of her future regret, she isn't making a mistake.

However, TRP doesn't yield the right results for all considerations and in all cases. Specifically, TRP's general applicability becomes questionable in cases that involve decisionmaking over possible transformative experiences. Recall that these are experiences that have the power to change our values, our priorities, and our self-conceptions. When faced with transformative choices, we should therefore not presume that the prospect of future regret implies that what will be regretted in the future is itself tracking something we rationally should already care about. We may not presently be in a position to care about the underlying consideration that the predicted regret would be tracking. Moreover, we may not be able to evaluate whether the future regret would be warranted due to our epistemically impoverished position. Epistemic poverty here is different from willful or imprudent ignorance. When we are aware that we are poised to make a transformative choice, we need to recognize certain key information is inaccessible to us at present. We would have to undergo the experience itself to gain access to the phenomenal qualities of that experience and for it to be revealed who we'll become as a result of that experience. Such a future regret is therefore not necessarily indicative that one has made a mistake.

This goes back to the question of whether our regrets are warranted only in situations where we recognize that we have made a mistake. While Jacobson claims that regret is only warranted in situations where a mistake in judgment has been made, I want to suggest that in 
the face of transformative experiences, regret is warranted in other situations as well. This is because transformative experiences are revelatory - they reveal certain features of our world and our selves that we could not have known antecedently (Paul 2014).

To understand this point, step back and ask: What are the ways in which we can end up regretting (and endorsing) transformative choices? I don't regret my decision to taste vegemite for the first time. It turned out to be delicious and nothing like I ever tasted before. Similarly, I don't regret my decision to taste hákarl for the first time either, though it turned out to be foul. The experience on the whole was noteworthy. While I will never do it again, the badness of the outcome associated with the taste of the fish does not outweigh the goodness of having the satisfaction of really knowing what it tastes like. There is nothing about the choice that I wish to undo. Having a novel experience of eating disgusting things thus has the power to contribute to my well-being because it involves a worthwhile revelation. There is subjective value in having certain new experiences just for the sake of discovering what these experiences are like or what it will be like to be me as the result of having these experiences (Paul 2014, 112-123). My decision to taste hákarl does motivate me to never eat hákarl again. But at the same time, this does not constitute a policy change about whether or not to be open to trying new delicacies when the opportunity arises.

However not all revelations are worthwhile. I do regret my decision to taste a really fancy glass of wine for the first time. The wine turned out to be delicious, but the experience made it impossible for me to enjoy Two Buck Chuck and I will rarely get the chance to drink that sort of fancy wine again. While the experience had much subjective value, in the long run it changed my evaluative perspective in such a way that made me worse off. Having novel experiences of drinking delicious things may contribute to my well-being but these contributions can be outweighed by the change in my evaluative set that make other experiences which I previously enjoyed less valuable. This is a trivial illustration, but the phenomena it illustrates can run deep as has been chronicled by Jennifer Morton in discussing the ethical costs that first generation students face as they go to college: "We rarely tell students that their success may come at the expense of some of the things that they hold most dear their relationships with family and friends, their connection to their communities, and their sense of who they're and what matters to them" (Morton 2019). Certain revelatory and transformative experiences have the power to change us in ways that we may end up regretting, even as we recognize that the experiences themselves are terrific and valuable.

What our regret is assessing in response to these transformative choices is not the subjective value of the outcomes of our choices, but the way these choices reveal to us what is valuable about the world and what kind of person we can become in the process of undergoing those experiences. After all, regret is an emotional response to the totality of how things have turned out for us and an important feature of how things have turned out for us is how we have turned out as a result of our choices.

My regret over tasting fancy wine tracks a significant loss for me. I no longer have the capacity to appreciate certain experiences that I had previously cherished. However, I don't take my choice to have been a mistake at the time. I took a risk in indulging in this revelatory experience, and to my chagrin it didn't pay off. Does this mean that my regret over tasting this fancy wine is unwarranted? D'arms and Jacobson seem to think so. They claim, "The errors of policy that count as regrettable - that is, fitting to regret - include only those errors that 
you could and should have known were mistakes" (D'arms and Jacobson 2011, 192). This is the criterion of fit for them because the distinctive motivating feature of regret is that it should motivate us to resolve to act differently next time. Without some assessment that we have actually made a mistake, there can be no policy change. This criterion of the fittingness of regret, however, does not take into account the possibility of transformative experiences and how living through such experiences can themselves motivate policy changes without our retrospectively judging that we "could and should have known were mistakes" prior to undergoing them. We can learn about the badness of our choices by bearing the burden of their consequences. Our regrets that result from transformative experiences can thus motivate policy changes without us thinking that we made any mistake in the past.

So far, I have considered a number of proposals for how predicting future regret has a role to play in the deliberations depicted in the three cases. On the Hedonic Approach, it's the pain of future regret that serves as a tie-breaker in our present decision-making. On the Heuristic for Mistaken Judgment Approach, the prediction that one will regret a decision in the future indicates that making such a decision in the present is a mistake. Both of these approaches have been found to be inadequate for thinking about the medical decisions in cases that involve transformative choices. The Hedonic Approach is inadequate because it doesn't seem that the pain of regret should be an important consideration, given the significant medical decisions that people are making. The Heuristic for Mistaken Judgment Approach doesn't take seriously the possibility that transformative experiences reveal to us new, formerly inaccessible information and can change our evaluative set. If the information was formerly inaccessible than it could not have been a mistake to not take it into account in our decisionmaking. Our regret can be warranted even if no mistake was made either because we couldn't have known better or because we shouldn't have known better - that is, we were indeed different prior to the revelatory experience - what we cared most about was different and what should have been salient to us was different.

\section{COMPARING APPROACHES THAT TAKE INTO ACCOUNT TRANSFORMATIVE CHOICES}

So how are we to consider regret in a way that takes seriously the transformative nature of one's choices? I don't think there is going to be one universal principle such as TRP that can guide us. Rather different contexts are going to make the specter of regret relevant to our deliberation in different sorts of ways. There are however going to be wrong ways to consider our future regret in practical reasoning. In this section, I will examine four approaches that may tempt us:

Approach 1: Predicting future regret about one option and doing the opposite

Approach 2: Comparing Levels of Predicted Regret (Vaccine Case)

Approach 3: Comparing Likelihoods of Regret (Abortion Case)

Approach 4: Future Regret as a way to reevaluate the salience of present preferences (Chemo Case)

Consider Approach 1. On this approach, we straightforwardly determine that some course of action is not justified because we predict that we'll come to regret it. I am thinking about buying a house. I predict that I will end up regretting the choice and so I take myself to be justified in not buying it. This approach seems straightforward enough. Unfortunately, this 
approach cannot be employed on its own in order for us to arrive at justified decisions regardless of whether we are confronting a transformative choice. This is because there are many scenarios in which we can expect to feel regret no matter what we do (Jacobson 2013, 120). Buying and renting are both expensive and anxiety-inducing undertakings. Neither alternative is thus justified based solely on our predicted regrets (Howard 2015, 365). There may be other considerations that will help us make rational decisions, but our predicted regrets for each course of action taken on their own remain normatively silent.

It follows that whatever approach we are going to take, it's important that anticipated emotions of each alternative option are taken into account. These sorts of comparisons prove challenging in the face of transformative choices, since each alternative can lead to outcomes in which not only has one gained access to new information but also one's evaluative set has changed. Consider the case of Vaccination Regret. What the vaccination study seems to suggest is that people are predicting that one outcome is going to lead to a higher level of regret than another outcome. They are thus following what I take to be Approach 2: comparing intensity levels of the predicted regret for each outcome and choosing the option they think will lead to a lower level of regret. There are two possible ways to understand the motivation behind such an approach:

A. We could imagine people thinking, "If something bad happens to my child as a result of my decision to vaccinate, I will regret it more than if something bad were to happen to my child as a result of my decision to not vaccinate."

Or alternatively,

B. We could imagine people thinking, "It will be more regrettable if something bad were to happen as a result of my decision to vaccinate my child than if something bad were to happen as a result of non-vaccination."

Neither of these ways of considering one's future regret will work in the face of transformative experiences. In response to A, comparing the intensity level of regret that one predicts one would feel in response to each options is a non-starter because one can only predict the intensity of regret if one has subjective access to what it will be like to have undergone the particular experience. However, the phenomenal texture of these experiences isn't the sort of things that we can imaginatively anticipate. While the child's negative health outcomes may turn out to be similar in each case, we should not think that these two experiences are one and the same. If the experiences themselves are inaccessible at present, the affective character of our regret responding to each experience is also subjectively inaccessible at present. In response to B, we should note that this is just sneaking in our current evaluative judgments into our predictions of the future regret. While we now think that one outcome is more regrettable than another, we have yet to undergo the transformative experience and what we consider more regrettable may change. So the prediction that we'll feel a more intense level of regret if we take one option rather than another isn't going to be an appropriate justification for our transformative choices.

However what if the comparison we are making isn't the intensity level of our predicted regrets but rather the likelihood of feeling regret at all? This is Approach 3, and I take 
it that it's the approach that is meant to be employed in the case of Abortion Regret. When abortion opponents are claiming that "abortion begets regret in more cases than childbearing begets regret," what they're essentially saying is that having an abortion puts one at greater risk for making a choice that one will come to regret. What we should make of this case is for now hypothetical, since the claim that a substantial amount of women come to regret their abortions has not been borne out by the evidence (Adler 2000; Major et. al. 2000; Greasely 2016; Ginsberg Dissent in Gonzalez v. Carhart 2008). If it turned out that having an abortion puts one at a greater risk of future regret, would this fact in itself constitute a reason to forgo the procedure?

Approach 3 is an improvement over the first two in how it can respond to the prospect of transformative experiences. What we are comparing in Approach 3 isn't any phenomenal features of what it will be like to bear the consequences of one choice or another, nor are we comparing the intensity level of our regret over one choice or another, rather we are simply determining the likelihood of our future regrets. Furthermore, we can make this sort of determination without at present negatively judging the potential outcomes of our choices nor do we need to presently understand what it is about our choice that will make the regret warranted. All we need to make this determination is base our predictions on the retrospective attitudes of others who have undergone similar experiences and who were similarly situated prior to the experience (Pettigrew 2015). Approach 3 also counteracts some of the cognitive biases that become manifest when we attempt to predict our future regrets from our first personal perspective. We tend to anticipate feeling more regret than we actually end up feeling about any given situation (Gilbert et. al. 2004). By basing our predictions on the regret that others actually feel, our predictions may more accurately reflect the likelihood that we'll actually end up regretting the choice.

There is, however, a note of caution regarding the relevance of basing our predictions of regret on the testimony of others in certain domains: testimony may often be an unreliable measure and may be post-hoc so difficult to evaluate. In some contexts, people are pretty bad at assessing the subjective value of the decisions they have made. As Paul argues, "claims like 'I can't imagine life without my child' are not evidence that having a child has high subjective value; they're merely evidence that having a child impairs a parent's psychological ability to envision certain counterfactual scenarios" (Paul 2014, 89; Harman 2009). This psychological inability is surely an admirable feature of being a parent, given one's reasonable attachments and the way that things turned out (Wallace 2013). However we should approach such testimony with caution when it comes to making decisions about whether to choose to form certain attachments in the first place. While we may become the sort of people who would regret such choices post transformation, we are not yet such people, so it is unclear why the testimony of people post-transformation be relevant to us now.

One further note of caution about this note of caution: there could be an asymmetry between the reliability of expressions of regret as compared to the reliability of expressions of endorsement. We all have psychological mechanisms in place to counteract self-blame and negative retrospective attitudes such as regret and remorse. People are frighteningly good at adapting to their circumstances. This may suggest that when people actually do consistently express regret over a certain decision that this indeed is tracking something about the choice that is of great disvalue and that is difficult to disregard. This asymmetry is underexplored in 
the psychological literature, but it suggests that testimony related to regrets may be more reliable than testimony related to endorsements.

How does all this inform our understanding of Abortion Regret? First, given the difference between social norms pertaining to expressions of regret for abortion and expressions of regret for having children, we should be skeptical about the accuracy of statistical evidence drawn from the general population. Moreover, how having an abortion affects a person (i.e. transformative or not, regretted or not) is highly individuated and may not be the sort of thing you can predict about yourself even if you have accurate information about the general population (Barnes 2015). Approach 3 may thus be a useful strategy for incorporating one's predicted future regrets, but it is a strategy that may be prone to inaccuracies and it can be difficult to assess what implication these general retrospective attitudes have in relation to particular individuals.

Most problematically, basing one's decisions on these sorts of anticipated regrets, which are themselves beholden to the empirical data about the retrospective attitudes of others, is a deeply impersonal way to engage in decision-making about things that really matter to us and can have lasting effects on our life. In this sense, Paul argues that we are "alienated" from our choices when "[w]e lack the ability to epistemically "see" these future utilities from the subjective perspective" (2015b, 801). Approach 3 may thus accurately incorporate one's possible regrets into one's decision-making but it comes at the cost of failing to make one's decision from an authentically first-personal perspective. What is left of the individual decision-maker employing Approach 3? This sort of decision, determined by the general risks of regret that attach to certain choices, could just as easily have been made on her behalf by her doctor or by a judge or by lawmakers.

\section{MAY ONE AUTHENTICALLY ACCOUNT FOR ANTICIPATED REGRET?}

In closing, I turn to Approach 4, considering one's future regret as a way to reevaluate the salience of one's present preferences and available options. This approach is the one that seems to be most applicable in the case of Chemo Regret. Imagine a patient who is deliberating about whether to undergo ASCT and it is brought to her attention that a significant portion of other patients who have undergone ASCT have regretted it and have claimed that if the severity of the treatment could be fully understood prior to the ordeal, they wouldn't have agreed to it. What is the patient to make of such a consideration?

She could take an impersonal approach like Approach 3 and measure the likelihood of her being one of the people who end up regretting the procedure compared to the likelihood of being able to tolerate the procedure. But I think she has a different and more personal approach available to her as well. The fact that others who have gone through similar ordeals end up regretting the decision can refocus the patient's attention on some features of her predicament that she may be presently underrating.

Imagine that this person has already undergone chemotherapy, so prior to hearing about the testimony of others, she was confident she knew what the discomfort associated with ASCT entailed. After considering the possibility of her future regret, she may come to see things differently. Before considering future regret, the prospect of intense (but comprehensible) pain did not count as a decisive consideration against the ASCT, but after 
hearing the testimony of others she may come to realize the pain she may yet endure isn't the sort thing she can imaginatively anticipate.

She may ask herself, how bad does this pain have to be for me to end up regretting my decision to undergo a treatment that can save my life? Will I too regret this choice? This can be a significant consideration in her decision-making, not because the patient is assigning extra disutility to the future pain, but rather because the patient comes to recognize that she isn't in an epistemic position to be able to prospectively assign a subjective value to that pain. Accordingly, the prediction that ACST will warrant post-treatment regret can make a normative difference to the patient now. This is not by requiring her to be able to assess the subjective value of the future pain, but rather by making her aware of her condition of epistemic poverty in relation to her possible future phenomenal experiences. The patient is in a better epistemic position than the prior position of those who have undergone ASCT before her who did not consider their possible future regret because at least she is made acutely aware of what she does not and cannot know.

In this sense, the specter of regret does serve a heuristic of sorts. Rather than being indicative that one is about to make a mistake, or that there is some underlying value that one already cares about but is overlooking, the prediction that one will regret a decision in the future makes one confront that her present values and priorities may change as a result of her choice in ways she cannot presently anticipate.

Is this strategy of considering the possibility of one's future regret authentic. That is, does it enable the patient to shape her life from a distinctive first-personal perspective? There is a clear sense in which this patient does not have psychological access to her future self. She is blocked from being able to imaginatively project herself into the future. But there is another sense in which one's anticipated regret is constitutively first-personal. David Velleman has argued that "to wonder how much of the future I can anticipate experiencing is just to wonder how far in the future there will be experiences that I am now in a position to prefigure firstpersonally" (Velleman 1996, 68). When one is considering one's future retrospective attitudes, such as regret and remorse, one is projecting a future perspective which features one's present self as the projected perspective's past self. When we anticipate regret, we don't only imagine the consequences that will make our future regret warranted, we also imagine that in the future, we'll be emotionally responding to the actions we had once chosen. The first kind of imaginative anticipation - of the phenomenal qualities of one's future experience - may be opaque to us. The second kind of imaginative anticipation - of the fact that in the future there will still be a "me" there who reacts to and must live with the choices that I am trying to make right now - does not seem so opaque.

Even if I cannot know what it will be like to be me in the future after my transformation, I can point out that this future me will remember that I was once in a really tough spot facing a baffling transformative choice and trying to figure out whether to take the plunge. Our predicted regrets don't let us completely sever the subjective ties we have with our prospective future selves - even if those selves end up being radically different and unimaginable to us at present. In other words, while I have discussed many pitfalls to such reasoning, considering future retrospective emotions like regret in our decision-making can be both rational and authentic even when we necessarily draw evidence from the experience of others. 


\section{References}

Adler, Nancy (2000) “Abortion and Null Hypothesis" Archive of General Psychology 57: 785-6.

Barnes, Elizabeth (2015). Social identities and transformative experience. Res Philosophica.

Connolly, Terry and Reb, Jochen (2003) 'Omission Bias in Vaccination Decisions: Where's the 'Omission'? Where's the 'Bias'? Organizational Behavior and Human Decision Processs 91, 186202.

D'arms, Justin and Jacobson, Daniel (2000) "The Moralistic Fallacy: On the 'Appropriateness' of Emotions” Philosophy and Phenomenological Research 61 (1): 65-90.

D'arms, Justin and Jacobson, Daniel (2011) "Regret and Irrational Action" Reasons for Action. Ed. David Sobel and Steven Wall. Cambridge: Cambridge University Press. 179-199.

Gilbert, Daniel; Morewedge, Daniel; Risen, Jane; and Wilson, Daniel (2004) Looking Forward to Looking Backward” Psychological Science 15 (5): 346-50.

Greasely, Kate (2012) “Abortion and Regret” Journal of Medical Ethics 38:705-711

Harman, Elizabeth (2009) "'I'll be glad I did it' reasoning and the significance of future desires" Ethics. Ed. John Hawthorne 177 -199.

Howard, Dana (2015) “Transforming Others” Res Philosophica, 92 (2): 341-71.

Jacobson, Daniel (2013) "Regret, Agency, and Error" Oxford Studies in Agency and Responsibility Vol. 1. Ed. David Shoemaker. Oxford: Oxford University Press.

Liptak, Adam (2016) "Eyes on Kennedy, Women Tell Supreme Court Why Abortion Was Right for Them," New York Times, February 29, 2016

https://www.nytimes.com/2016/03/01/us/politics/abortion-supreme-court-womenexplain-choices.html. Accessed, Dec. 21, 2020

Little, Miles et al. (2008) "Informed Consent and Medical Ordeal: A Qualitative Study," Internal Medicine Journal 38 (2008) 624-628

Little, Miles (2009) “The Role of Regret in Informed Consent” Bioethical Inquiry 6:4959. 
Loewenstein, George and Schkade, David (1999) “Wouldn't it be Nice? Predicting Future Feelings", in Well-being, ed. D. Kahneman, E. Diener, and N. Schwartz (New York: Russell Sage Foundation).

Norton, Jennifer (2019) Moving Upward Without Losing Your Way: The Ethical Costs of Upward Mobility. Princeton, NJ: Princeton University Press.

Major, Brenda; et al. (2000) "Psychological Responses of Women After first-trimester abortions" Archive of General Psychology 57: 777-84.

Moller, Dan (2011) “Anticipated Emotions and Emotional Valence" Philosophers' Imprint. 11 (9): 1-16

Paul, L. A. (2014) Transformative Experiences. Oxford: Oxford University Press.

Paul, L. A. (2015a) “What You Can't Expect When You're Expecting.” Res Philosophica $92(2): 149-171$.

Paul, L. A. (2015b) "Precis of Transformative Experiences." Philosophy and Phenomenological Research. XCI (3): $760-813$.

Pettigrew, Richard (2015) "Transformative experience and decision theory." Philosophy and Phenomenological Research 91.3: 766-774.

Wallace, R. Jay (2013) The View From Here. Oxford: Oxford University Press.

Walsh, Emily (2020) Cognitive Transformation, Dementia, and the Moral Weight of Advance Directives, The American Journal of Bioethics, 20:8, 54-64.

Velleman, David (1996) “Self to Self' The Philosophical Review. 105 (1): 39-76.

Ziarnowski, Karen, et al. (2009) "Present choices, future outcomes: Anticipated regret and HPV vaccination." Preventative Medicine. 48(5): 411-4.

Zeelenberg, Marcel (1999) “The Use of Crying Over Spilled Milk." Philosophical Psychology 12 (3): 325-340 